Trauma Surgery \& Acute Care Open

\title{
Penetrating gluteal injuries in North West London: a retrospective cohort study and initial management guideline
}

\author{
Gerard Hywel Owen McKnight, 1,2 Seema Yalamanchili, 2,3 Natalia Sanchez-Thompson, ${ }^{2}$ \\ Nadia Guidozzi, ${ }^{2}$ Natasha Dunhill-Turner, ${ }^{2}$ Alex Holborow, ${ }^{4}$ Nicola Batrick, ${ }^{2}$ \\ Shehan Hettiaratchy, ${ }^{2}$ Mansoor Khan, ${ }^{2}$ Elika Kashef, ${ }^{2}$ Chris Aylwin, ${ }^{2}$ Dan Frith ${ }^{2}$
}

\begin{abstract}
- Additional supplemental material is published online only. To view, please visit the journal online (http://dx.doi. org/10.1136/tsaco-2021000727).
\end{abstract}

'Institute of Naval Medicine, Royal Navy, Gosport, UK 2Major Trauma, Imperial College Healthcare NHS Trust, London, UK

${ }^{3}$ Division of Surgery and Cancer, Imperial College London Faculty of Medicine, London, UK ${ }^{4}$ Department of Radiology, Swansea Bay University Health Board, Swansea, UK

\section{Correspondence to} Gerard Hywel Owen McKnight; gerardmcknight8@hotmail.com

Received 17 March 2021 Accepted 22 June 2021 (c) Author(s) (or their employer(s)) 2021. Re-use permitted under CC BY-NC. No commercial re-use. See rights and permissions. Published by BMJ.

\begin{tabular}{l}
\hline To cite: \\
McKnight GHO, Yalamanchilis, \\
Sanchez-Thompson N, et al. \\
Trauma Surg Acute Care Open \\
2021;6:e000727. \\
\hline
\end{tabular}

\section{ABSTRACT}

Background Penetrating gluteal injuries (PGIs) are an increasingly common presentation to major trauma centers (MTCs) in the UK and especially in London. PGIs can be associated with mortality and significant morbidity. There is a paucity of consistent guidance on how best to investigate and manage these patients. Methods A retrospective cohort study was performed by interrogating prospectively collected patient records for PGI presenting to a level 1 MTC in London between 2017 and 2019.

Results There were 125 presentations with PGI, accounting for $6.86 \%$ of all penetrating injuries. Of these, $95.2 \%$ (119) were male, with a median age of 21 (IQR 18-29), and 20.80\% (26) were under 18. Compared with the 3 years prior to this study, the number of PGI increased by $87 \%$. The absolute risk (AR) of injury to a significant structure was $27.20 \%$; the most frequently injured structure was a blood vessel (17.60\%), followed by the rectum (4.80\%) and the urethra (1.60\%). The AR by anatomic quadrant of injury was highest in the lower inner quadrant (56\%) and lowest in the upper outer quadrant (14\%). CT scanning had an overall sensitivity of $50 \%$ and specificity of $92.38 \%$ in identifying rectal injury.

Discussion The anatomic quadrant of injury can be helpful in stratifying risk of rectal and urethral injuries when assessing a patient in the emergency department. Given the low sensitivity in identifying rectal injury on initial $\mathrm{CT}$, this data supports assesing any patients considered at high risk of rectal injury with an examination under general anesthetic with or without rigid sigmoidoscopy. The pathway has created a clear tool that optimizes investigation and treatment, minimizing the likelihood of missed injury or unnecessary use of resources. It therefore represents a potential pathway other centers receiving a similar trauma burden could consider adopting.

Level of evidence $2 \mathrm{~b}$.

\section{BACKGROUND}

Penetrating gluteal injuries (PGI) are an important presentation to urban major trauma centers (MTCs) in the UK. Although low in number, representing between $1 \%$ and $3 \%$ of all trauma team activations, there is evidence to show they are increasingly prevalent in London. Recent studies from one MTC revealed a fourfold increase in presentation during a 2-year period. ${ }^{12}$ Due to the specific inclusion criteria of the UK Trauma Audit and Research Network database, many of these cases are not captured, leading to underestimation of the presentation in national data. ${ }^{3}$ Despite this, these injuries can lead to significant morbidity, affecting the gastrointestinal, vascular and nervous systems, and mortality of up to $10 \% .{ }^{4}$ Furthermore, these injuries are associated with occult intra-abdominal injuries in up to $50 \%$ of patients. $^{5}$

There has been widespread publicity on the increasing incidence of knife crime in the UK, particularly the extent to which it is concentrated in the heavily populated urban centers such as London and Birmingham. ${ }^{6}$ UK Home Office data show a steady annual rise in knife offenses in England and Wales since 2014, with offenses $80 \%$ more frequent in $2019 .{ }^{6}$ This data also demonstrate that Greater London continues to have the greatest burden of knife crime, with 169 offenses per 100000 of the population. The second highest region was the North West of England, reporting just over half of this figure (93 knife offenses per 100000 population). ${ }^{6}$ The increase in reported crime has also been associated with a $42 \%$ increase in hospital admissions for knife injuries in England during the same time period. ${ }^{7}$

The exact motive for an individual act of violence is hard to ascertain; however, there is some evidence that the gluteal region is deliberately targeted-a practice also known as bagging or dinking. ${ }^{8}$ This appears to be motivated by such attacks carrying a lower risk to life but having potential for injury and sequelae perceived as degrading, such as a colostomy . PGIs risk damage to the rectum, significant vasculature, sciatic nerve, and urogenital tract. Despite the increasing incidence of presentation and the significant associated morbidity, there remains a paucity of published data on the topic. Although there is more data from the military context, this is often limited to ballistic injury, rather than lowenergy penetrating mechanisms. ${ }^{9-12}$

Appreciation of potential wound trajectory and thorough clinical examination are essential for identifying structures at risk and deciding imaging accordingly. Many UK MTCs and trauma units use a combination of clinical examination and CT imaging as first-line investigations, with subsequent procedures decided by specialist teams thereafter, although there is little guidance on what constitutes 
best practice. This is especially the case for initial management in the emergency department (ED), despite the pitfalls of missed injury.

This single-center, retrospective cohort study analyzed data from a London MTC from 2017 to 2019 to assess the chronological incidence of PGI due to assault by a sharp weapon and to characterize anatomic variants associated with significant occult injury. Findings were combined with expert opinion to develop a decision-making pathway to improve future management of these injuries in a contemporary civilian trauma setting.

\section{METHODS}

St Mary's Major Trauma Centre is the tertiary trauma referral hospital for the North West London Major Trauma Network and receives approximately 3000 trauma patients per year. All patients presenting to St Mary's Major Trauma Centre with penetrating injury to the gluteal region during a 3-year period from January 1, 2017 to December 31, 2019 were identified from the local electronic trauma database. The electronic health records of these patients were then reviewed in detail to collect data on patient demographics, anatomic distribution of the wound, associated rectal, vascular, or nerve injury, initial investigations, and surgical or radiological interventions. Patients presenting with wounds secondary to gunshot wound (GSW) were excluded as this is a very different pattern of injury and has been well studied elsewhere. The anatomic limits of the gluteal region were defined as the gluteal fold inferiorly, the posterior superior iliac spine superiorly, and the greater trochanter laterally. All injuries included in this data set were posterior to the trochanters, and due to the gluteal injury rather than any other associated injury in the case of a patient with multiple injuries. This was due to the recognized increase in this injury pattern locally. ${ }^{1}$ Vascular injury was defined as either presence of active bleeding or injury to a vessel seen on CT imaging. Data was collected and analyzed using Microsoft Excel V.16.16 (Microsoft, Seattle, USA), and further statistical analysis was performed using R V.4.0.2 ( $\mathrm{R}$ Core Team, Vienna, Austria). The study is reported in concordance with the Strengthening the Reporting of Observational Studies in Epidemiology guidelines. ${ }^{13}$ Categorical data is presented as a percentage followed by number and was analyzed for statistical significance using Fisher's exact test. Continuous data is presented as a median followed by IQR. The denominator for all percentages was the total injuries unless explicitly stated. A p value of less than 0.05 was considered significant.

CT scan type was recorded as being either a 'combi' scan (single-phase CT) or a dual-phase/triple-phase CT. Combi scans use a biphasic intravenous contrast protocol with a single acquisition, whereas a dual-phase or triple-phase CT scan uses intravenous contrast with either two or three acquisitions, respectively. ${ }^{14}$

\section{RESULTS}

During the 3-year study period, 125 patients with PGI were identified, accounting for $1.39 \%$ of all trauma cases and $6.86 \%$ of all penetrating injuries. Of these patients with PGI, 95.2\% (119) were male, with a median age of 21 (IQR 18-29), and $20.80 \%$ (26) were under 18. Just over half of patients with PGI $(52.8 \%)$ were admitted to hospital from the ED, with a median length of stay (LOS) of 1 day (0-2) and a mean LOS of 1.46 days. The chronological distribution of PGI across the study period is given in table 1 . There were three cases of GSW, who all presented in 2018; these were excluded from the data set as the mechanism
Table 1 Chronological distribution of PGI and percentage of total penetrating injuries

\begin{tabular}{llcl}
\hline Year & Total penetrating trauma & PGI & $\begin{array}{l}\text { Percentage of } \\
\text { PGI }\end{array}$ \\
\hline 2017 & 640 & 47 & 7 \\
2018 & 634 & 48 & 7 \\
2019 & 559 & 30 & 5 \\
\hline $2017-2019$ & 1833 & 125 & 7 \\
\hline
\end{tabular}

PGI, penetrating gluteal injury.

of injury is very different from that of a stab wound. Of the PGI cohort, 2 patients (1.6\%) had sustained 'accidental injury' and the remaining 123 patients (98.4\%) had been assaulted by a sharp weapon.

\section{Chronological distribution}

The chronological distribution of patients remained relatively static across the study period, as outlined in table 1. Analysis of the temporal distribution demonstrates three clear peaks at 17:00, 19:00, and midnight, which was consistent across the 3 years studied (figure 1). However, subset analysis of the under-18 cohort reveals that the majority of these injuries occur earlier in the afternoon, soon after the school day finishes, between 16:00 and 17:00 (figure 2).

Table 2 compares the number and percentage of PGI in the 3 -year study period with the preceding 3 years. This revealed an increase of $43 \%$ in total penetrating trauma and $87 \%$ in the number of presentations with PGI.

\section{Anatomic distribution}

Although there were 125 patients in the data set, several of them were injured multiple times, giving a total number of wounds of 141. A significant structure was defined as a confirmed injury to the rectum, urethra, prostate, sciatic nerve, or named blood vessel. The overall absolute risk (AR) of injury to a significant structure was $27.2 \%$ per patient over the entire cohort (table 3 ).

There were 22 vascular injuries $(20.00 \%$ of all patients), 6 $(4.80 \%)$ rectal injuries, $1(0.80 \%)$ mesorectal laceration, and 2 $(1.60 \%)$ urethral injuries, with $1(0.80 \%)$ of these urethral injuries extending to the prostate. There were two $(1.60 \%)$ possible sciatic nerve injury suggested on CT; however, one was ruled out after a normal clinical examination and the second patient absconded before this could be confirmed operatively. The distribution of the injuries according to the quadrant of the buttock can be found in figure 3 .

Although the vascular injuries were spread relatively evenly across the quadrants, five out of the six confirmed rectal injuries were found in patients who had entry wounds in the lower inner quadrant $(p=0.0577)$. The patients stabbed in the lower inner quadrant of the buttock had an AR of rectal injury of $18.52 \%$ and an AR of $55.56 \%$ for injury to any significant structure.

\section{Investigations}

The vast majority of our patients received neither a digital rectal examination (DRE) nor a rigid sigmoidoscopy (RS) in the ED (table 4), and the percentage of patients receiving either of these examinations in the ED declined during the study period, from $26 \%$ in 2017 to $10 \%$ in 2019.

A total of 113 CT scans were performed for 111 patients, meaning $88.80 \%$ of patients received a CT scan. The remaining 14 patients $(11.20 \%)$ were discharged after thorough clinical 


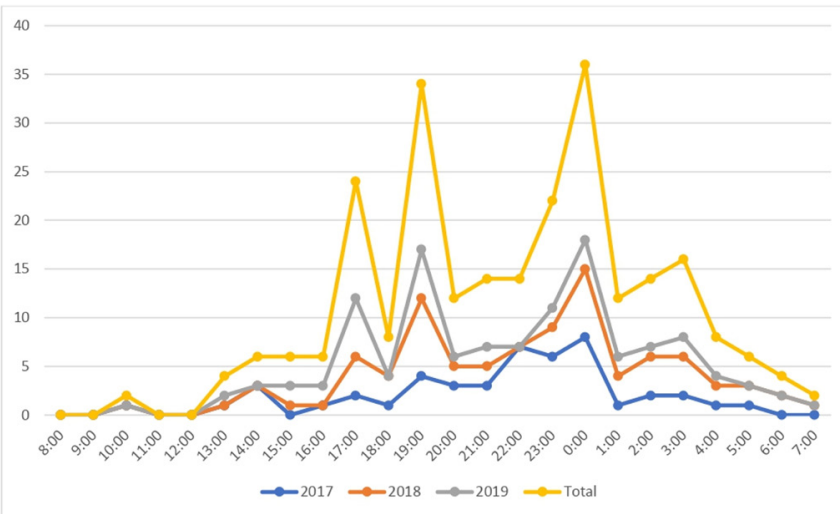

Figure 1 Temporal distribution of penetrating gluteal injuries.

assessment, with the trauma team leader (TTL) deciding that there was no need for CT. Rectal contrast was only used in two patients $(1.60 \%)$. There was equal split in the type of CT used to assess these patients, with dual-phase or triple-phase contrast CT being used with almost the same frequency as a single-phase combi CT scan (table 5). There were eight false positive CT findings and four false negative CT findings, giving an overall sensitivity of $50.00 \%$ and specificity of $92.38 \%$ in identifying rectal injury on initial assessment. From this data, combi CT had a sensitivity of $50 \%$ and a specificity of $94.55 \%$, whereas dualphase or triple-phase CT had a sensitivity of $50 \%$ and a specificity of $90.00 \%$.

\section{Management}

The most common procedure required for these injuries was debridement, washout, and delayed primary closure of the entry wounds. This was performed in 26 patients by a variety of specialties. The median time from arrival to the hospital to operative intervention was 724 minutes (293-1047), or 12 hours and 4 minutes.

As displayed in table 6 there were 13 vascular injuries, 69.23\% (9) were treated conservatively, 30.77\% (4) underwent embolization, and $7.69 \%$ (1) also underwent an endovascular repair of an arteriovenous fistula. When assessing vascular injuries, major bleeding was considered present if the patient was alerted as a 'code red' by prehospital ambulance teams or if the patient received at least one unit of blood product in the ED.

Of the six rectal injuries shown in table 7, 16.67\% (1) were primarily repaired during an examination under anesthetic (EUA), with a drain left in situ, 33.34\% (2) were treated with

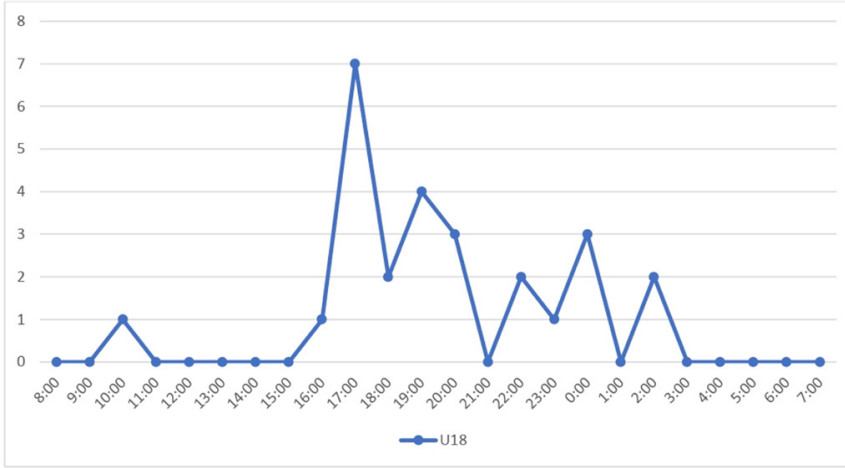

Figure 2 Temporal distribution of penetrating gluteal injuries in under 18s (U18).
Table 2 Comparison with 3 years preceding this study

\begin{tabular}{lccl}
\hline & $\mathbf{2 0 1 4 - 2 0 1 6}$ & $\mathbf{2 0 1 7 - 2 0 1 9}$ & \% increase \\
\hline Total penetrating & 1272 & 1831 & 43 \\
Total PGI & 67 & 125 & 87 \\
\% PGI & 5 & 7 & \\
\hline
\end{tabular}

PGI, penetrating gluteal injury.

washout and packing only, and 50.00\% (3) were treated with proximal diversion, 2 of which were colostomies and 1 an ileostomy due to congenital adhesions affecting the sigmoid colon. There was one additional patient who suffered an injury to the mesorectum with no injury to the rectal wall; this patient was managed with oversewing of the mesentery during trauma laparotomy.

\section{DISCUSSION}

These results from a 3-year period highlight the management challenges in the treatment of patients presenting with a PGI to one urban UK MTC, including the potential for damage to a wide range of structures and the varied options for investigation and intervention. This study has shown that the quadrant of injury can be helpful in identifying those patients most at risk of rectal and urethral injuries early on in their presentation. However, quadrant of injury was not found to be helpful in predicting vascular or nerve injuries. Those patients with a PGI in the lower inner quadrant of the gluteal region had an AR of $18.52 \%$ for rectal injury and $55.56 \%$ for injury to any significant structure. Although this did not reach statistical significance, it is most likely due to the study population size. From this dataset the authors suggest that those patients with an injury to the lower inner quadrant are considered at high risk of rectal injury, and knowledge of this should contribute to the threshold applied for further investigation. Patients with multiple PGIs should be treated according to the clinical suspicion raised by the injury associated with the greatest anatomic risk. Therefore, any patient with a wound in the lower inner quadrant should be treated as high risk of rectal injury, irrespective of the locations of other injuries.

In keeping with a national trend of increasing knife crime, this study showed that the overall volume of penetrating trauma has increased by $44 \%$ and the volume of PGI has increased by $87 \%$ compared with the previous 3 years. This reflects local data from another level 1 trauma center within the same city. ${ }^{1}$ There may be some inaccuracy with the older data in this study due to slightly less mature data systems and processes of data capture; however, there is evidence that the regional increase in the presentation has been part of a nationwide increase in knife crime. ${ }^{6}$ Due to the complex behavioral and socioeconomic factors associated with knife crime, it is difficult to propose the

Table 3 Absolute risk (AR) of significant structure injury by quadrant of injury

\begin{tabular}{ll}
\hline Quadrant & AR (\%) \\
\hline Upper outer & 20 \\
Upper inner & 14 \\
Lower outer & 17 \\
Lower inner & 56 \\
Overall per wound & 24 \\
Overall per patient & 27 \\
\hline
\end{tabular}




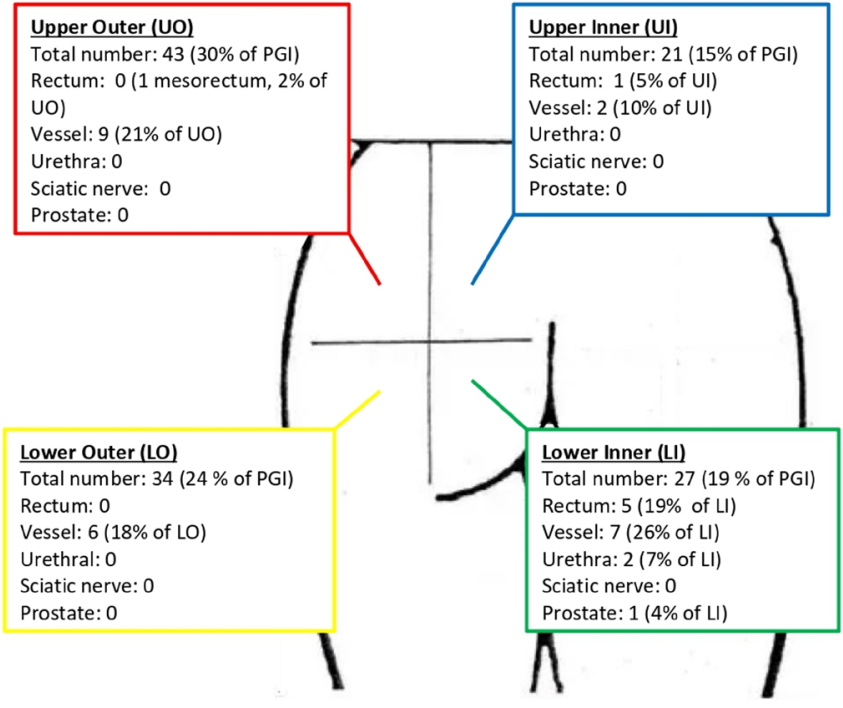

Figure 3 Anatomic distribution of penetrating gluteal injuries (PGI).

reasons behind the increase in PGI; however, anecdotally there remains a stigma within this cohort around these injuries and the associated stoma, suggesting that there is a degree of purposeful anatomic targeting.

This study excluded wounds from GSW, which are relatively rare in the UK, and this may explain the lower mortality compared with other literature from settings where GSW is more common, that is, military or civilian contexts outside Europe. However, the peak in presentations among under $18 \mathrm{~s}$ at around 16:00-17:00 highlights the end of the school day as the time of highest risk of assault with a weapon for adolescents. This is consistent with patterns of knife assault in London established previously. ${ }^{15}$

\section{Investigation of PGI}

The decrease in proportion of patients receiving DRE and RS in the ED is reflective of international consensus, moving away from mandating these tests in all patients and instead using RS in selected cases as a useful adjunct. RS is used at our institution to confirm or refute the presence of a rectal injury and to identify the anatomic location of any injury that can affect further management, and can be done as part of an EUA in the theater rather than performed in the ED. This is considered more likely to yield identification of rectal injury due to the controlled theater environment and be more acceptable to the patient who may find this intolerable in the ED.

There are widespread, and justifiable, reservations about the utility of DRE in assessing for rectal injury, with a previous 2007 study reporting a sensitivity of only 33\% (specificity 99\%) based on a retrospective analysis of over a thousand patients. ${ }^{16}$ In another study from 2005, the DRE was shown to give 'useful information' in only 5\% of cases and changed

\begin{tabular}{lc}
\hline $\begin{array}{l}\text { Table } 4 \text { Clinical examinations performed in the emergency } \\
\text { department }\end{array}$ \\
\hline Examination & $\mathbf{n}(\%)$ \\
\hline Digital rectal examination & $13(10)$ \\
\hline Rigid sigmoidoscopy & $11(9)$ \\
Nil & $98(78)$ \\
Refused & $3(2)$ \\
\hline
\end{tabular}

management in only $4 \% .{ }^{17} \mathrm{RS}$, on the other hand, has been found to have a much higher sensitivity of $94 \%$ in one largescale retrospective study of 22 level 1 trauma centers, which was better than CT in identifying both intraperitoneal and extraperitoneal injuries. The same study found that RS in combination with CT gave an overall sensitivity of $97 \% .^{18}$ RS can be useful in determining the anatomic location of a rectal injury which, given the trend toward managing intraperitoneal injuries and extraperitoneal injuries differently, can aid decision-making for surgical teams. ${ }^{4}$

The decision on which patients underwent CT was made by the TTL at the time of presentation after a thorough clinical examination. The choice of CT protocol was inconsistent across the study period, with an almost 50:50 split between triple-phase or dual-phase CT and 'combi' CT scan. The specificity of CT in detecting rectal injury improved during the study period, which could reflect growing familiarity and experience among reporting radiologists during the time since this unit was established as an MTC in 2010.

Although contrast-enhanced CT is the default imaging in the severely injured trauma patient, penetrating injury to the bowel can be difficult to confirm on CT and is most commonly identified by locules of gas or inflammatory stranding in adjacent soft tissue. ${ }^{1}$ The gold standard noninvasive investigation is a 'triple contrast' CT (with oral, intravenous, and rectal), being quoted with a sensitivity of $97 \%$ and a specificity of $98 \%$ for diagnosis of peritoneal breach in penetrating torso injury; this is, however, impractical in the acute setting and seldom used at our center. ${ }^{19-21}$ The authors of one military case series of 19 patients with no missed rectal injuries concluded that a CT scan can be a useful screening tool to help identify which patients warrant further investigation. ${ }^{22}$

Given that in our population CT had a sensitivity of $50.00 \%$ and specificity of $92.38 \%$ in identifying rectal injury on initial assessment, these data support having a low threshold for assessing any patients at high risk of rectal injury with direct visualization, either with an EUA $( \pm$ RS) in the operating theater for an extraperitoneal injuries or with a diagnostic laparoscopy for intraperitoneal injuries. Although the decision of what constitutes a high-risk patient for rectal injury will vary from clinician to clinician, the authors suggest that those with rectal bleeding or radiological evidence of bowel wall breach or thickening, presence of a wound tract extending to the bowel or mesentery, or adjacent mesenteric hematoma or stranding should be investigated with an EUA in the theater as these indications are supported by recent literature. ${ }^{181921}$ While noting that no individual CT finding can be considered both sensitive and specific to bowel injury, the authors also suggest that patients with presence of air or fluid near the bowel wall on CT should also be considered for either observation, serial clinical examination and repeat imaging, or an EUA in the theater at the discretion of the responsible clinician. ${ }^{19} 21$

\begin{tabular}{|c|c|c|c|}
\hline Type of CT scan & $\mathrm{n}$ & Sensitivity (\%) & Specificity (\%) \\
\hline Single-phase combi scan & 57 & 50 & 95 \\
\hline Dual-phase/triple-phase scan & 56 & 50 & 90 \\
\hline No CT scan & 14 & - & - \\
\hline
\end{tabular}


Table 6 Vascular injuries

\begin{tabular}{llll}
\hline Quadrant of injury & Major bleeding & Vessel injured & Management \\
\hline Not recorded & Yes & Branch of the right inferior gluteal artery. & Embolization. \\
\hline LI & Yes & $\begin{array}{l}\text { Arterial bleeding within the left bulbocavernosus muscle, arterial bleeding within the } \\
\text { left obturator externus muscle, extending into the left prostate peripheral/central zone. } \\
\text { Arterial/venous bleeding into the rectal lumen. }\end{array}$ & Conservative. \\
\hline LI & Yes & Right internal pudendal artery. & Conservative. \\
Not recorded & No & Intramuscular branch (gluteal). & Conservative. \\
UO & No & Intramuscular branch (gluteal). & Conservative. \\
UO & No & Branch of the right superior gluteal artery. & Embolization. \\
\hline LO+LI & No & Active venous and arterial bleeding from the small branches of the left deep artery and & Embolization. \\
LI & No & Bleeding from profunda femoris+arteriovenous fistula. & Embolization+endovascular repair of \\
& & arteriovenous fistula.
\end{tabular}

$\mathrm{LI}$, lower inner; LO, lower outer; UI, upper inner; UO, upper outer.

\section{Management of colorectal trauma}

The management of rectal trauma has traditionally centered on 'the Four D's' of debridement, diversion, drainage, and distal washout. However, this was based on the Allied military experience during World War II and the US military experience during the Vietnam War, where the pattern and mechanism of injury were vastly different from that seen in UK civilian trauma practice outside of major terrorist incidents. ${ }^{24} 23$ One of the few prospective studies on colon trauma by Demetriades et al ${ }^{24}$ recommended considering primary anastomosis in all patients with colon trauma and identified severe fecal contamination, transfusion of $>4$ units of blood products within the first 24 hours, and single-agent antibiotic prophylaxis as the only independent risk factors for abdominal complications.

Recent literature has proposed a more nuanced approach to the management of colon and rectal injuries based on the degree of injury and the anatomic location of the injury, in conjunction with other patient factors such as comorbidity, presence of hemorrhagic shock, and concurrent injuries. ${ }^{2} 425$ Clemens et $a l^{4}$ have proposed a treatment algorithm based on the size and location of rectal injury in relation to the peritoneal reflection. In this pathway, an injury affecting greater than $25 \%$ of the circumference of the rectum is considered 'destructive' and those affecting less than 25\% 'non-destructive'. Non-destructive extraperitoneal injuries are treated either by primary repair if accessible or conservatively with admission and observation. Destructive extraperitoneal injuries are treated with proximal fecal diversion without presacral drainage. Rectal washout is recommended for selected, high-energy injuries only. Intraperitoneal injuries are treated by primary repair if non-destructive and with primary resection and anastomosis if destructive. ${ }^{426} 27$

Of particular importance when considering repair of colorectal injury is the presence of concomitant vascular injury. These cases have reported mortality as high as $36 \%$. This supports a lower threshold to treat these patients with proximal diversion rather than anastomosis; however, this evidence originates from a military case series of high-energy battlefield injuries. ${ }^{4} 28$

The more nuanced approach is supported by a recent metaanalysis that recommends primary repair or resection with anastomosis in colon trauma unless patients are critically unwell or undergoing damage control surgery (DCS) as these patients have a significantly higher rate of anastomotic leak. ${ }^{29}$

Given all the injuries in our data set were low-energy wounds from sharp objects and all extraperitoneal injuries, it is perhaps surprising that half of these injuries were managed with fecal diversion. Two $(33.34 \%)$ of these patients were recognized to have a potentially destructive extraperitoneal injury during EUA and so were appropriately managed with a defunctioning

\begin{tabular}{|c|c|c|}
\hline Quadrant & Injury & Management \\
\hline $\mathrm{LI}$ & Extraperitoneal, anterior+posterior rectal injury, $>25 \%$ circumference. & Diagnostic laparoscopy+defunctioning ileostomy. Reversed 5 months later. \\
\hline LI & 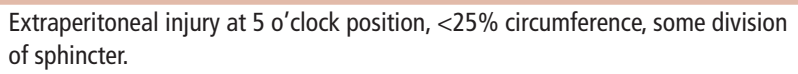 & Rectum sutured+drain inserted. Diagnostic laparoscopy normal. \\
\hline LI & $\begin{array}{l}\text { Suspected extraperitoneal rectal injury }<25 \% \text { circumference. } \\
\text { Intramural blood, blood, and feces obscuring view on RS, large mesorectal } \\
\text { hematoma on diagnostic laparoscopy. }\end{array}$ & Laparoscopic loop colostomy, reversed 3 months later. \\
\hline LI & Anal sphincter injury, $<25 \%$ circumference. & Washout+packing. \\
\hline UI & Extraperitoneal injury, $25 \%$ of circumference, $6-9$ o'clock $8 \mathrm{~cm}$ from anal verge. & Laparoscopic loop colostomy. Reversed 6 months later. \\
\hline $\mathrm{LI}$ & $\begin{array}{l}\text { Extraperitoneal, laceration } 2 \mathrm{~cm} \text { from anal verge extending radially to around } 4 \\
\mathrm{~cm},<25 \% \text { circumference. External anal sphincter fibers seen. }\end{array}$ & EUA+packing of rectum+RS+second look EUA. \\
\hline
\end{tabular}

EUA, examination under anesthetic; LI, lower inner; RS, rigid sigmoidoscopy; UI, upper inner.

McKnight GHO, et al. Trauma Surg Acute Care Open 2021;6:e000727. doi:10.1136/tsaco-2021-000727 


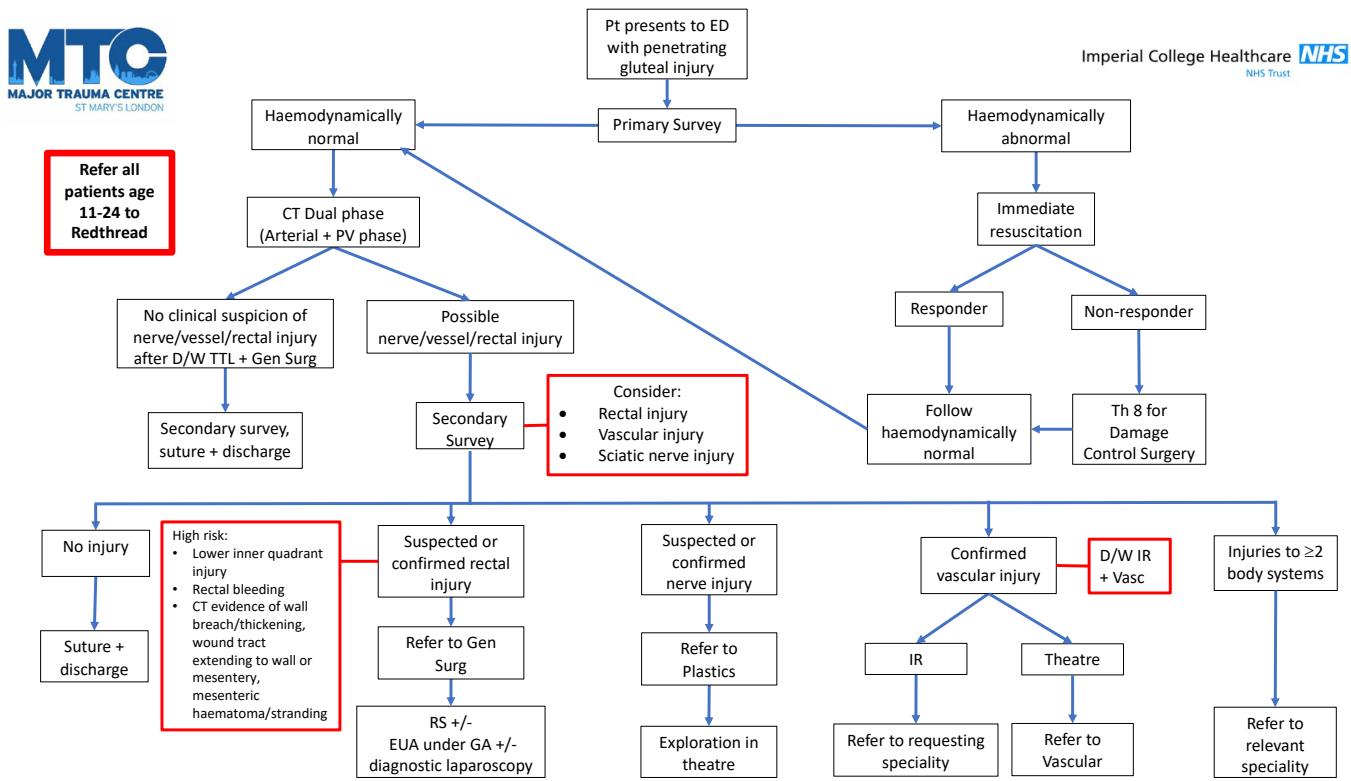

Figure 4 St Mary's pathway for penetrating gluteal injuries. Pt; patient, D/W; discuss with, ED; emergency department, CT; computed tomography, PV; portal venous,EUA; examination under anesthetic, GA; general anaesthetic, Gen Surg; general surgery, IR; interventional radiology, Redthread; local violence reduction charity, RS; rigid sigmoidoscopy, TTL; trauma team leader; Vasc; vascular surgery.

stoma. It could be argued that the one remaining rectal injury treated with a defunctioning stoma could have been initially managed with either primary repair or conservative management following current international guidance. ${ }^{42} 29$ This may represent unfamiliarity with the international guidelines, or there may have been other patient-related or surgeon-related factors that were beyond the remit of this study.

\section{A suggested pathway for management of PGI}

Based on the findings of this study, we have identified a need for a pathway providing a systematic and consistent approach to the assessment and initial management of patients presenting with a PGI. A pathway was designed to address the areas of greatest variation and based on previous literature, the evidence from this study, and expert opinion of surgeons, emergency medicine physicians, and radiologists from our MTC. This pathway (figure 4) describes the assessment and initial management, whereby following primary survey and resuscitation, or DCS where required, all patients are imaged with a dual-phase CT scan to assess the risk of rectal, vessel, and nerve injury. The quadrant of injury is useful to help identify high-risk patients for rectal and urethral injury, but is one component of a thorough clinical assessment in combination with judicious use of radiological investigations. As part of the algorithm the authors use $\mathrm{CT}$ as a screening tool to identify any immediate life-threatening injuries, such as major hemorrhage or intra-abdominal visceral injury. Those patients deemed to be at high risk of an injury to a vessel, the rectum, or sciatic nerve are then referred to the appropriate specialty for further investigation and management. The data from this study suggest that a CT scan cannot be used to confidently rule out a rectal injury; therefore, where there is clinical suspicion of rectal injury, an EUA, RS, and/or a diagnostic laparoscopy should be performed depending on the suspected anatomic location of injury. The authors recommend the use of a dual-phase CT (with arterial and portal venous phases) to allow for accurate assessment of any vascular injury and allow for efficient planning of any interventional radiological procedure without the need for a return to CT. The pathway has created a clear tool that various specialties feeding into a multidisciplinary trauma team can refer to. This ensures optimized investigation and treatment, minimizing the likelihood of missed injury or unnecessary use of resources. It therefore represents a potential pathway other centers receiving a high proportion of low-energy PGIs could also consider incorporating into practice.

\section{CONCLUSION}

PGIs are an important presentation to trauma centers, carry a significant risk of morbidity and are increasingly common among our patient population. The findings are consistent with other literature on low-energy penetrating injury, particularly knife crime in the UK, and add nuance to the literature on gluteal injury, which has been weighted toward high-energy mechanisms. The results also highlight ongoing diurnal trends in violence, particularly among young people toward the end of the school day, further contributing to the discussion on how to best address this public health issue. Finally, this work has demonstrated how the anatomic quadrant of injury can be helpful in stratifying risk of rectal and urethral injuries when assessing a patient with a PGI. The subsequently suggested pathway may assist receiving trauma teams in the initial management of these patients by ensuring thorough assessment and evidencebased multidisciplinary team management to avoid treatment dilemmas and pitfalls, including missed injury.

Acknowledgements The authors would like to thank Joanne Graves, Major Trauma Service Manager at St Mary's Major Trauma Centre, for her invaluable work in maintaining the Major Trauma Registry.

Contributors This study was designed and directed by NB, SH, CA, DF, SY, and GHOM. GHOM, NG, NS-T, and ND-T were responsible for collection of data. GHOM, NG, ND-T, and SY were responsible for data analysis. AH was responsible for statistical analysis. The article was written by GHOM and SY and critiqued by all authors.

Funding The authors have not declared a specific grant for this research from any funding agency in the public, commercial or not-for-profit sectors. 
Competing interests None declared.

Patient consent for publication Not required.

Ethics approval Ethics approval was not required as this was registered as a clinical audit and approved by the local Clinical Audit Committee (audit reference number TRA_72).

Provenance and peer review Not commissioned; externally peer reviewed.

Open access This is an open access article distributed in accordance with the Creative Commons Attribution Non Commercial (CC BY-NC 4.0) license, which permits others to distribute, remix, adapt, build upon this work non-commercially, and license their derivative works on different terms, provided the original work is properly cited, appropriate credit is given, any changes made indicated, and the use is non-commercial. See: http://creativecommons.org/licenses/by-nc/4.0/.

\section{REFERENCES}

1 Campion T, Cross S. The spectrum of injuries in buttock stab wounds. Clin Radiol 2017;72:543-51.

2 Johnson EK, Steele SR. Evidence-Based management of colorectal trauma. J Gastrointest Surg 2013;17:1712-9.

3 Malik NS, Munoz B, de Courcey C, Imran R, Lee KC, Chernbumroong S, Bishop J, Lord JM, Gkoutos G, Bowley DM, et al. Violence-related knife injuries in a UK City; epidemiology and impact on secondary care resources. EClinicalMedicine 2020;20:100296

4 Clemens M, Peace K, Yi F. Rectal trauma: evidence-based practices. Clin Colon Rectal Surg 2018:31:017-23.

5 American College of Surgeons. ATLS course manual. advanced trauma life support course manual. , 2018:17, 1-88.

6 Office for National Statistics. Offences involving the use of weapons. focus violent crimes sex offences Compend. , 2019:1, 1-25. https://www.ons.gov.uk/peoplepopula tionandcommunity/crimeandjustice/datasets/offencesinvolvingtheuseofweaponsdata tables.

7 NHS Digital. Hospital Admissions for Assault by Sharp Object [Internet]. 2019. https:// digital.nhs.uk/data-and-information/find-data-and-publications/supplementaryinformation/2019-supplementary-information-files/hospital-admissions-for-assault-bysharp-object.

8 Lydall R. Stab victim medics reveal how London gangs try to maim their targets, not kill, and use screwdrivers and spoons to beat knife laws. Evening Standard [Internet]. 2014. https://www.standard.co.uk/news/london/london-stab-victim-medics-extremeviolence-call-to-stop-knife-crime-brutality-9939397.html.

9 Cho SD, Kiraly LN, Flaherty SF, Herzig DO, Lu KC, Schreiber MA. Management of colonic injuries in the combat Theater. Dis Colon Rectum 2010;53:728-34.

10 Hudolin T, Hudolin I. The role of primary repair for colonic injuries in wartime. Br J Surg 2005:92:643-7.

11 Uravić M. Colorectal war injuries. Mil Med 2000;165:186-8.

12 Steele SR, Wolcott KE, Mullenix PS, Martin MJ, Sebesta JA, Azarow KS, Beekley AC. Colon and rectal injuries during operation Iraqi freedom: are there any changing trends in management or outcome? Dis Colon Rectum 2007:50:870-7.
13 von Elm E, Altman DG, Egger M, Pocock SJ, Gøtzsche PC, Vandenbroucke JP, . STROBE Initiative. The strengthening the reporting of observational studies in epidemiology (STROBE) statement: guidelines for reporting observational studies. J Clin Epidemiol 2008;61:344-9.

14 Hakim W, Kamanahalli R, Dick E, Bharwani N, Fetherston S, Kashef E. Trauma wholebody MDCT: an assessment of image quality in conventional Dual-phase and modified biphasic injection. Br J Radiol 2016;89:20160160.

15 Vulliamy P, Faulkner M, Kirkwood G, West A, O'Neill B, Griffiths MP, Moore F, Brohi K. Temporal and geographic patterns of stab injuries in young people: a retrospective cohort study from a UK major trauma centre. BMJ Open 2018:8:e023114:1-6.

16 Shlamovitz GZ, Mower WR, Bergman J, Crisp J, DeVore HK, Hardy D, Sargent M, Shroff SD, Snyder E, Morgan MT. Poor test characteristics for the digital rectal examination in trauma patients. Ann Emerg Med 2007;50:25-33.

17 Esposito TJ, Ingraham A, Luchette FA, Sears BW, Santaniello JM, Davis KA, Poulakidas SJ, Gamelli RL. Reasons to omit digital rectal exam in trauma patients: no fingers, no rectum, no useful additional information. J Trauma 2005;59:1314-9.

18 Trust MD, Veith J, Brown CVR, Sharpe JP, Musonza T, Holcomb J, Bui E, Bruns B, Andrew Hopper $\mathrm{H}$, Truitt $\mathrm{M}$, et al. Traumatic rectal injuries: is the combination of computed tomography and rigid proctoscopy sufficient? I Trauma Acute Care Surg 2018;85:1033-7.

19 Shanmuganathan K, Mirvis SE, Chiu WC, Killeen KL, Hogan GJF, Scalea TM. Penetrating torso trauma: triple-contrast helical $\mathrm{CT}$ in peritoneal violation and organ injury--a prospective study in 200 patients. Radiology 2004;231:775-84.

20 Board of the Faculty of Clinical Radiology. Standards of practice and guidance for trauma radiology in severely injured patients rcr standards, 2010:1-23.

21 Khan I, Bew D, Elias DA, Lewis D, Meacock LM. Mechanisms of injury and CT findings in bowel and mesenteric trauma. Clin Radiol 2014;69:639-47.

22 Johnson EK, Judge T, Lundy J, Meyermann M. Diagnostic pelvic computed tomography in the rectal-injured combat casualty. Mil Med 2008;173:293-9.

23 Lavenson GS, Cohen A. Management of rectal injuries. Am J Surg 1971;122:226-30.

24 Demetriades D, Murray JA, Chan L, Ordoñez C, Bowley D, Nagy KK, Cornwell EE, Velmahos GC, Muñoz N, Hatzitheofilou C, et al. Penetrating colon injuries requiring resection: diversion or primary anastomosis? an AAST prospective multicenter study. $J$ Trauma 2001;50:765-75.

25 Ahern DP, Kelly ME, Courtney D, Rausa E, Winter DC. The management of penetrating rectal and anal trauma: a systematic review. Injury 2017;48:1133-8.

26 Bosarge PL, Como JJ, Fox N, Falck-Ytter Y, Haut ER, Dorion HA, Patel NJ, Rushing A, Raff LA, McDonald AA, et al. Management of penetrating extraperitoneal rectal injuries: an eastern association for the surgery of trauma practice management guideline. J Trauma Acute Care Surg 2016;80:546-51.

27 Brown CVR, Teixeira PG, Furay E, Sharpe JP, Musonza T, Holcomb J, Bui E, Bruns B, Hopper HA, Truitt MS, et al. Contemporary management of rectal injuries at level I trauma centers: the results of an American association for the surgery of trauma multi-institutional study. J Trauma Acute Care Surg 2018:84:225-33.

28 Arthurs Z, Kjorstad R, Mullenix P, Rush RM, Sebesta J, Beekley A. The use of damage-control principles for penetrating pelvic battlefield trauma. Am I Surg 2006;191:604-9

29 Tang MH, Wong JSH, Chia CLK, Lee DJK. Meta-Analysis on surgical management of colonic injuries in trauma: to divert or to anastomose? Eur J Trauma Emerg Surg 2021 [Epub ahead of print: 04 Jan 2021] 